\title{
Work motivation and self-rated anxiety: Nurses' perspectives
}

\author{
Ibrahim Yahya Alhakami*1, Omar Ghazi Baker ${ }^{2}$ \\ ${ }^{1}$ Jeddah Psychiatric Hospital, Nursing Administration Department, Kingdom of Saudi Arabia \\ ${ }^{2}$ Department of Nursing Administration \& Education Department, College of Nursing, King Saud University, Riyadh, Kingdom \\ of Saudi Arabia
}

Received: April 25, 2018

DOI: $10.5430 /$ cns.v6n4p69
Accepted: June 13, 2018

Online Published: June 26, 2018

\begin{abstract}
Objective: Considering nurses' psychological status, work decision involvement, emotions, anxiety, and motivation, is an important issue for attaining nurses' retention and maintaining their preservation in their work positions. Work motivation is the key that enhances employee performance which is influenced by numerous internal and external factors; job anxiety is the apparent one. The current study is directed to achieve two aims: to assess the work motivation level and self-rated anxiety among nurses and to investigate the relationship between them. Therefore, a descriptive, correlative research design was applied with 300 registered nurses in King Abd El Aziz governmental hospital in Jeddah, Saudi Arabia.

Methods: A triple-section questionnaire was used for data collection that involved: First, Multidimensional Work Motivation Scale (MWMS) that was developed by Gagne et al. in 2010. Second, Self-Rated Anxiety Sub-scale which was developed by Warr et al. in 1979. Third, sociodemographic questions were included.

Results: About three-quarters of Suadi nurses have high work motivation level concerning introjected and identified regulations while more than half of them have a high level of work motivation regarding amotivation and extrinsic regulations. Consequently, most of the participants have high scores in work motivation level. As regards, self-rated anxiety, all study subjects have a certain level of anxiety at work, but the majority of them were with low level. As pertaining the correlation between both study variables, there is a negative correlation between work motivation level and self-rated anxiety and the present study proved that Saudi registered nurses in King Abd El Aziz governmental hospital have high work motivation level scores with low self-rated anxiety scores.

Conclusions: The current study confirms that the Saudi nurses in Jeddah have high work motivation level with low anxiety. Furthermore, the study provides evidence of a negative or inverse correlation between work motivation level and self-rated anxiety among Saudi registered nurses in King Abd El Aziz governmental hospital. Nurses should be aware by the importance of motivation in their job and at the same time, be aware of the risks of work-related anxiety. Nurse Managers have to tailor all factors which are surrounding nurses in a hospital environment, organizational structure and culture to be positively motivated and, at the same time, to alleviate any tendency of work-related anxiety. Furthermore, work motivation and anxiety should be involved and integrated into the nursing curriculum in nursing schools.

Further researches: A research about the effect of the work motivation educational program on nurse manager's leadership skills, is needed. A study about the correlation between work motivation and other negative or positive variables in work environment among nurses is necessitated. Also, assessment of nurses' work motivation and anxiety using different tools such as value test, emotional inventory and adjustment skills measurement.
\end{abstract}

Key Words: Work motivation, Self-rated anxiety, Nurses

*Correspondence: Ibrahim Yahya Alhakami; Email: aa.1hh@ hotmail.com; Address: Jeddah Psychiatric Hospital, Nursing Administration Department, Kingdom of Saudi Arabia.

Published by Sciedu Press 


\section{INTRODUCTION}

Work motivation is "a prerequisite for better organizational performance". It was reported as "the processes that account for an individual's intensity, direction, and persistence of effort toward attaining a goal". As a general rule, motivation stems from a need which could drive, fulfill, enhance a specific behavior. Consequently, work motivation in nursing practice has an essential role in health care outcomes, if the work environment is prepared, and retention is sufficient. ${ }^{[1-4]}$

According to self-determination theory, the person who internally or externally motivated is working for own internal favor and gratification. There are three types of motivation regulation styles should be recognized by nurse manager: First, amotivation that refers to the stopping motivation in any directions of action. Second, the intrinsic motivation that happened when the person does the task or the action for own sake and favor, due to the one's feeling of interesting and pleasurable in doing. Third, the extrinsic motivation that refers to do the task or the activity for instrumental explanations, for instance; incentives, recognition, alleviating penalties, good comments and appreciation, all lead to improving one's self-esteem and direct toward ones' targets. This theory depends on the level of perception, recognition or orientation of internal and external motivation by the person. ${ }^{[5-7]}$ Therefore, the nurse can be committed (internally) to an excellent performance by motivation, guidance, and enhancement (externally).

For work motivation, and according to the previous classifications of motivation types which discussed by selfdetermination theory, those types were divided into five categories and explained more deeply by Gagne in 2010 . To increase the level of motivation among employees; five subtypes employed and shaped employees' motivation in different work settings: Amotivation, Extrinsic Motivation, Intrinsic Motivation, Introjected Motivation, and Identified Motivation. Amotivation is the absence of any motivation, so the employees do behaviors that directed to stop the undesired performance. Extrinsic Motivation is the least self-determined aspect, and that entails behaviors of compliance, looking for external incentives and keeping away from punishment at work. Also, it includes work circumstances, environment and organizational features that empower employees to work, such as work status, peers' cooperation, effective policies and regulations, superior directions and guidance and salaries. Relatively, Intrinsic Motivation represents the employees' interesting in achieving the work tasks. It is the major self-determined type and reflected a great self-happiness and work satisfaction. Nurses who are internally and inherently motivated will demonstrate enjoyable work performance. Introjected Motivation corresponds to the overall association of the ego and employee value which depends upon performance. High level of this type has own changeable values according to achievement in work. For example, nurse considers good patient health and competent nursing care are personal values, and their self-esteem is linked with those values. Employees with a strong extent of introjected type, are doing their best to keep their reputation and image in work. Furthermore, the Identified Motivation is concerning the tasks that are occurring through personal awareness, needs, and confidence, because the employees are conscious of those tasks' importance. In the same time, those tasks are congruent with the employee's values and desires. Those tasks can be pleasurable, or not, but it should be significant to be achieved. Nurses with an elevated degree of identified motivation, almost are searching for work that helps them to attain their goals in life and matches their values. Identified regulation helps to enhance being satisfied in work according to self-valuing, personal accomplishment, self-appreciation, the perception of own responsibility to job tasks and employee development. ${ }^{[4-9]}$ Hence, motivation is a key concept in nursing practice and management, because it directs nurses' performance and competencies to achieve work targets. The internal or external motives have a great impact on controlling the nurses' work behaviors.

Motivated employees tend to achieve their work assignments optimally, and direct the organization to attain an effective and efficient position in the community. Moreover, work motivation empowers employees to meet the institutional hopes such as: carry out of work processes effortlessly ultimately and accomplish the organizational goals within a definite and intentional period. ${ }^{[3-5]}$ Accordingly, work motivation is a necessary instrument to modify and shape employee behaviors and its consequences to meet organizational desired outcomes.

Nurses are the ones who have the responsibility to accomplish health care objectives and should receive effective work motivation to reach these objectives. Thus, they should be with suitable and sufficient numbers, appropriately allocated across different nursing positions and geographical regions, at the same time, in various health settings. For retained them in their work position, they should receive proper work incentives. Rewards, suitable work condition, adequate salary, and vacations as external motives are good examples of organizational causes which positively reflected internally and affect nurses' performance. Those external factors should be assessed and tailored for nursing staff by the nurse manager. Furthermore, cooperation with respecting personal voice, positive relationship and understanding the individual difference, constructive directions, helping in performance and staff development, are important sources of work empow- 
erment and motivation on an organizational level. ${ }^{[5-7]}$ On the other hand, there are numerous internal factors around nurses have apparent effects on their work motivation and may produce a negative or positive impact on their work. Internal factors refer to competencies, talents and thinking process. Also, one's favorites, needs, own values, personal priorities and background factors (such as age, sex, social status, knowledge, skills, education, and position), emotions of fear and self-rated anxiety, are other examples of internal factors. ${ }^{[6,8,10]}$

Anxiety is an emotion represented by a disagreeable state of internal disorder, repeatedly comes with mal-nervous behaviors, mal-alertness, somatic complaints, and poor cognition. The feeling of anxiety in work is a negative emotion, and when it arises during work, it can lead to poor performance. It is frequently associated with muscle strain and tension, restlessness, tiredness and decreasing in concentration or induced cognitive confusion. Anxiety is found in all aspects of our life by certain degrees, but when it experienced regularly, the individual may suffer from an anxiety disorder and enter the thickness cycle. Globally, many pieces of evidence discussed that healthcare professionals have a lot of stressors, anxiety, and frustration which are affecting unconstructively on work satisfaction and motivation. Anxiety is a motivational factor that may disturb work performance, stability, and outcomes. As well, it can be a cause for leaving work and dissatisfaction or de-motivation, especially, among nurses. ${ }^{[6,11,12]}$ Work-related anxiety and how the employee perceives it, may have an insightful negative consequence on employee's perception, health, and well-being as a whole. In the case of nurses' work, this may as well, influence patient care, community, and organizational outcome at all.

Job-related anxiety is defined as a rigorous feeling of discomfort, uneasiness, and worry at the workplace or during work. The employee may feel anxiety in nursing work or any job when he/she confronted difficulties or challenging situations, such as poor communication and lack of acknowledgment, limited support and lack of motivation or internal conflicts. Furthermore, work anxiety may occur due to many reasons for instance; organizational structural alteration, organizational change, workflow accidents, lack of policies, poor supervision, and guidance, increase workload and job strains or constraints. Additionally, work time loss, work errors, absenteeism, and intolerable consequences are anticipated and led to nurses' stress and anxiety at work. ${ }^{[13,14]}$

Certainly, the organization authority and the nursing manager should handle and remove all circumstances that can increase work anxiety among subordinates and at the same time, empower all factors that can decrease it. Particularly

Published by Sciedu Press in nursing practice, the nurse manager should be aware and understand how the anxiety situations can be raised in the work climate and how it can be a dangerous factor in nurses' achievement. ${ }^{[5,14]}$ Healthcare organizations should work on improving nurse's psychological status and alleviate any work stress or anxiety factors to maintain nurse's retention, satisfaction, loyalty, and motivation.

Work motivation and self-rated anxiety are major job issues in nursing work that were discussed in the literature and observed in reality. ${ }^{[5,13-15]}$ The first is an essential tool for improving nursing practice and supervision. As well, it should be explored and investigated with its positive or negative factors to prepare a suitable motivational plan for nurses. The second variable should be essentially examined and determined by the nurse manager to adjust effective psychological climate for nurses in their work activities with conductive and constructive support. Both variables and their correlation are significant in nursing management and nursing paradigm.

\subsection{Aim and significance}

Nursing is a crucial task in any hospital or health setting. Nursing work is the most significant healthcare services all over the world, particularly in Kingdom of Saudi Arabia (KSA). Moreover, and wide-reaching, it is considering one of the foundations of the community and nation healthcare jobs. In many Arabian and non-Arabian countries, hospitals are suffering from nurses' turnover, shortage, and absenteeism which are extremely high and are affecting the healthcare outcome negatively. Considering nurses' needs, preferences and favorites are essential to the mission of the Saudi nurse manager to maintain, activate, sustain and improve nursing work. Healthcare stakeholders should consider nurses' work motivation and avoid any factors that can disturb or affect it negatively. ${ }^{[6,11,16]}$ Therefore, this study directed to accomplish two aims: First, explore and determine the level of work motivation and self-rated anxiety as perceived by nurses in Jeddah. Second, identify the relationship between those two variables.

\subsection{Research questions}

- What are the levels of work motivation and self-rated anxiety as perceived by nurses in King Abd El Aziz governmental hospital in Jeddah?

- What is the relation between the level of work motivation and self-rated anxiety as perceived by nurses in King Abd El Aziz governmental hospital in Jeddah?

\subsection{Research hypothesis}

There is a significant inverse relationship between work motivation level and self-rated anxiety as perceived by nurses in 
King Abd El Aziz governmental hospital in Jeddah.

\section{Materials \& Method}

The current study employed a descriptive correlation research design to validate the association between work motivation level and self-rated anxiety as perceived by nurses. Study participants were comprised of 300 nurses who registered in King Abd El Aziz governmental hospital in Jeddah, Saudi Arabia. The sample size was estimated by open epidemiological statistical information program. ${ }^{[17]}$ The sample was selected by stratified random sampling from nursing departments, then systemic random sampling from a list of total 851 registered staff nurses. The eligible criteria were: registered nurses, both sexes, having worked at least six months; having completed initial training in the hospital; being present at the hospital during the data collection period, and voluntarily consenting to participate in the study. The data collection tool was a triple-section questionnaire, which involved: First, Multidimensional Work Motivation Scale (MWMS) that was developed by Gagne et al. in 2010. ${ }^{[8]}$ It a 19-item Likert scale that was used for assessing both the level and the orientation of employees' work motivation based on employees' psychological response to different personal and organizational factors in the work situation and environment. It included five measurement regulations: intrinsic motivation level (3 statements), external regulation (6 Items), introjected regulation (4 Items) and identified regulation (3 Items). Plus the fifth aspect of motivation which is called amotivation (3 Items). Items were answered using a five-point scale, ranging from 1 (not at all for this reason) to 5 (exactly for this reason). The total score was ranged from 19 to 95 , regarding 19-32 indicates low work motivation level; 33-64 represents moderate work motivation level and 65-95 points to high work motivation level.

Second, Self-Rated Anxiety Sub-scale which was developed by Warr et al. in $1979,{ }^{[18]}$ as a tool of measuring the internal psychological status of the employee regarding the concerning or worrying circumstances in work and indicating self-rated anxiety level. It is one of eight subscales that developed by Warr for measuring the internal psychological status of the employee. Seven items were given against measuring five-point rating scale, ranging from 1 (not at all concerned) to 5 (extremely concerned). The total score was ranged from 7 to 35, regarding 7-14 indicates low Self-Rated Anxiety; 15-24 represents moderate Self-Rated Anxiety and 25-35 points too high Self-Rated Anxiety. Third: Personal profile questions were included.

A pilot study was implemented using the study tool on 33 registered nurses at the mentioned setting who were excluded from the study sample, and all modifications were done. The study instrument was submitted to a jury of four experts in Nursing Education, Community Health Nursing, Administration and Psychiatric nursing fields to ensure its applicability and content validity, and then the necessary adjustment was made. This instrument retested for reliability using test and re-test reliability that revealed $r \geq 0.7$ for both measurement scales.

\subsection{Ethical considerations}

Permission for data collection was obtained from King Abd El Aziz governmental hospital in Jeddah, Saudi Arabia. A written informed consent was taken from each one of the study participants who were announced that they have an entirely voluntary decision to participate in the study and to windrow at any point of the study. As well, they were reassured that there were no penalties or any adverse effects on their work appraisal. The study subjects were given the questionnaire in the attendance of the researcher to explain any vague questions. Anonymity was ascertained by instructing all study participants to avoid writing of their names on the study instrument.

\subsection{Statistical analysis}

Microsoft Excel was used for data coding entry. Data were double-entered and cross-checked. Data files were backed up and password protected. The Statistical Program for Social Sciences (SPSS, version 20) and Windows Version 7.0 were used in processing data. Data analysis started with preparatory activities such as the treatment of missing data, identification of outliers, and other data cleaning tasks involving repeated cycles of screening and editing of suspected data abnormalities. Results are treated and presented using descriptive statistics measures in the form of frequencies and percentages for qualitative variables. The responses on the variables described in Likert scale were scored to facilitate interpretation and calculation for the tests of significance. Spearman's rho was used for clarifying the difference between both study variables. Statistical significance was considered at $p$-value $<.05$ and confidence interval of $(95 \%$ CI).

\section{RESULTS}

\subsection{Participants profile}

Table 1 shows nurses' Sociodemographic profile and background as presented by number and percentage. The majority of nurses were females respectively (93\%), with considerably about half $(45.9 \%)$ of the subjects are younger nurses in twenties. The majority of the nurses $(89.3 \%)$ are bedside nurses, while, three-quarters of them $(75 \%)$ have bachelor degree qualification. For training duration, more than one-half 
of study participants $(35.7 \%, 21.3 \%)$ have training courses with length from two days to seven days.

According to the revealed scores from the Multidimensional Work Motivation Scale, Table 2 clarifies percent distribution of study subjects according to the low, moderate and high level of work motivation. About three-quarters of nurses $(70 \%, 72.4 \%)$ have high work motivation level concerning introjected and identified regulations while about half of them $(55 \%, 44.4 \%)$ have a high level of work motivation regarding amotivation and extrinsic regulations. The majority of study subjects have high scores in work motivation level in general.

Congruent with the data in Table 3, it clarifies percent distribution of study subjects according to their Self-Rated Anxiety scores; all study subjects have a certain level of anxiety at work, but the majority of them $(85 \%)$ having a low level of self-rated anxiety at work. Therefore, only minimal proportions of them have moderate or high Self-Rated Anxiety scores in work.

Table 1. Nurses' sociodemographic profile

\begin{tabular}{|c|c|c|}
\hline \multirow{2}{*}{ Sociodemographic profile } & \multicolumn{2}{|c|}{ Registered nurses $(\mathrm{N}=\mathbf{3 0 0})$} \\
\hline & No & $\%$ \\
\hline \multicolumn{3}{|l|}{ Gender: } \\
\hline - Male & 21 & 7.0 \\
\hline - Female & 279 & 93.0 \\
\hline \multicolumn{3}{|l|}{ Age category $(n=468)$ : } \\
\hline$\bullet \leq 30$ years & 130 & 45.9 \\
\hline - $30-40$ years & 97 & 34.3 \\
\hline - $\leq 40$ years & 56 & 19.8 \\
\hline \multicolumn{3}{|l|}{ Qualifications: } \\
\hline - Vocational diploma from medical school & 40 & 13.3 \\
\hline - Specialized education from healthcare college & 8 & 2.7 \\
\hline - Bachelor degree & 225 & 75.0 \\
\hline - Master degree & 4 & 1.3 \\
\hline - Diploma & 23 & 7.7 \\
\hline \multicolumn{3}{|l|}{ Staff position in hospital: } \\
\hline - ICU nurse & 13 & 4.3 \\
\hline - OR nurse & 15 & 5.0 \\
\hline - Head nurse & 4 & 1.3 \\
\hline - Nurse (including other positions) & 268 & 89.3 \\
\hline \multicolumn{3}{|l|}{ Training duration: } \\
\hline - None & 39 & 13.0 \\
\hline - 1 day & 42 & 14.0 \\
\hline - 2-4 days & 107 & 35.7 \\
\hline - 5-7 days & 64 & 21.3 \\
\hline - 8-10 days & 23 & 7.7 \\
\hline - 11 days or more & 25 & 8.3 \\
\hline
\end{tabular}

Table 4 reports the correlation and association between the level of work motivation and self-rated anxiety among study group as presented by numbers and percentages. It is evident that there is a converse proportion between both variables where Spearman's rho association test $r=-0.317$. A high percentage of registered nurses $(56 \%)$ who have low selfrated anxiety scores, is about, the same high percentage of

Published by Sciedu Press the registered nurses who have high work motivation scores, that definitely, congruent with the research hypothesis.

The extrapolative variables in the research study, have illustrated the variance of self-rated anxiety scores that represented low by nurses proportion $(56 \%)$, while identical percent is detected among study subjects who have high work motivation level. Alternatively, there were no regis- 
tered nurses who have high work motivation level and re- level correspondingly. The correlation coefficient among selfported high self-rated anxiety. Thus there was no percent for rated anxiety and work motivation is noteworthy opposite high work motivation level, among nurses with high anxiety relation.

Table 2. Percent distribution of study subjects according to their work motivation mean scores

\begin{tabular}{|c|c|c|}
\hline \multirow{2}{*}{ Multidimensional work motivation items } & \multicolumn{2}{|c|}{ Registered Nurses $(\mathrm{N}=\mathbf{3 0 0})$} \\
\hline & No. & $\%$ \\
\hline \multicolumn{3}{|l|}{ Amotivation } \\
\hline - Low & 82 & 27.3 \\
\hline - Moderate & 53 & 17.7 \\
\hline - High & 165 & 55 \\
\hline \multicolumn{3}{|l|}{ Extrinsic Regulation (social \& material) } \\
\hline - Low & 121 & 40.3 \\
\hline - Moderate & 46 & 15.3 \\
\hline - High & 133 & 44.4 \\
\hline \multicolumn{3}{|l|}{ Introjected Regulation } \\
\hline - Low & 53 & 17.6 \\
\hline - Moderate & 30 & 10 \\
\hline - High & 217 & 72.4 \\
\hline \multicolumn{3}{|l|}{ Identified regulation } \\
\hline - Low & 45 & 15 \\
\hline - Moderate & 45 & 15 \\
\hline - High & 210 & 70 \\
\hline \multicolumn{3}{|l|}{ Intrinsic regulation } \\
\hline - Low & 83 & 27.7 \\
\hline - Moderate & 53 & 17.7 \\
\hline - High & 164 & 54.6 \\
\hline \multicolumn{3}{|l|}{ Total score } \\
\hline - Low & 77 & 25.6 \\
\hline - Moderate & 45 & 15 \\
\hline - High & 178 & 59.4 \\
\hline
\end{tabular}

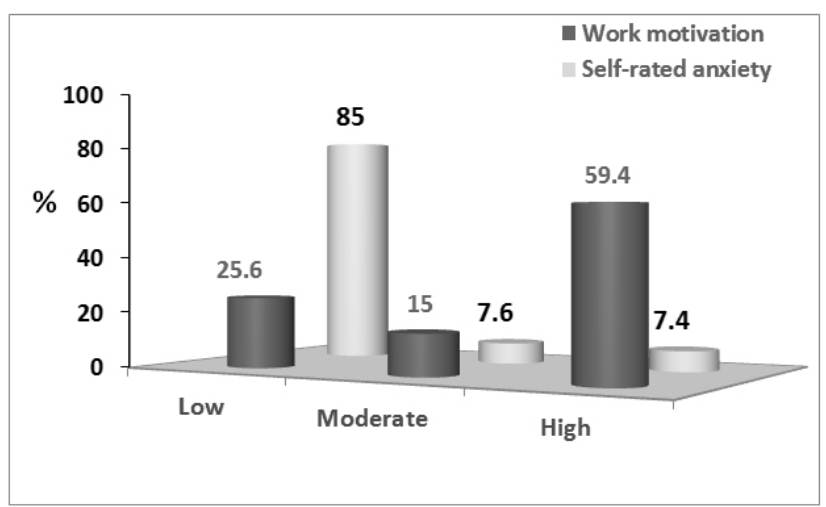

Figure 1. The correlation between nurses' level of motivation and self-rated anxiety scores as presented by percentage
Table 3. Percent distribution of study subjects according to their Self-Rated Anxiety scores

\begin{tabular}{lll}
\hline \multirow{2}{*}{ Self-Rated Anxiety scores } & \multicolumn{2}{c}{ Registered Nurses $(\mathbf{N}=\mathbf{3 0 0})$} \\
\cline { 2 - 3 } & No. & $\%$ \\
\hline Low & 255 & 85 \\
Moderate & 23 & 7.6 \\
Severe & 22 & 7.4 \\
\hline
\end{tabular}

Furthermore, Figure 1 demonstrates the correlation between nurses' level of motivation and self-rated anxiety scores as presented by percentage. A negative correlation is detected. This opposite relation is observed among nurses who reported low scores in work motivation, at the same time they have got high self-rated anxiety and vice versa. 
Table 4. Correlation between nurses' level of motivation and self-rated anxiety scores as presented by number and percentage

\begin{tabular}{|c|c|c|c|c|c|c|c|c|}
\hline \multirow{3}{*}{ Correlation } & & \multicolumn{6}{|c|}{ Self-Rated Anxiety (N = 300) } & \multirow{3}{*}{ Statistical test } \\
\hline & & \multicolumn{2}{|c|}{ Low $(n=255)$} & \multicolumn{2}{|c|}{ Moderate $(n=23)$} & \multicolumn{2}{|c|}{ High $(n=22)$} & \\
\hline & & No. & $\%$ & No. & $\%$ & No. & $\%$ & \\
\hline \multirow{3}{*}{$\begin{array}{l}\text { Level of } \\
\text { Motivation } \\
(\mathrm{N}=300)\end{array}$} & Low $(n=20)$ & 53 & 17.6 & 8 & 2.6 & 15 & 5 & \multirow{3}{*}{$\begin{array}{l}r=-0.317^{* *} \\
p=.004\end{array}$} \\
\hline & Moderate $(\mathrm{n}=12)$ & 34 & 11.4 & 4 & 1.4 & 7 & 2.3 & \\
\hline & $\operatorname{High}(n=48)$ & 168 & (53) & 11 & 3.6 & 00 & 0.00 & \\
\hline
\end{tabular}

Note. ${ }^{* *}$ Correlation Coefficient is significant at the 0.01 level (2-tailed); Spearman's rho used to quantify the strength of association between 2 numerical ordinal variables

\section{Discussion}

Nursing workforce is facing multiple stressors and difficulties and has necessitated for work motivation and recognition. They have many work demands because they are continuously confronted complicated situations when managing patients complains. Therefore, they are the most workgroup who have an intense need for work motivation. ${ }^{[6,19]}$ Work motivation and anxiety are significant work issues that should be handled and explored among nurse's managers. By the findings in the present study, the demographic profile of the participants shadowed that almost all of the study subjects were females and in their early twenties. This point clarified that men in nursing are still minimum ratio and femininity in nursing work still dominant. Congruent with this view, in Egypt, Abd El-Halem et al. in 2011 discussed that male in nursing has multiple chances to be a pioneer in such feminine work, but males are unmoving and considered a trivial workforce against females. ${ }^{[19,20]}$

Almost all of the study subjects were bedside nurses, where they already in touch with all practical, clinical and situational challenges and conflicts during patients' direct care. Of course, they provided rich data about their emotions and needs from their direct experiences. Matching with this result, nurses are the ones who have the responsibility of patients care, and face many obstacles in such work that may be resulted in frustration and overloading. Consequently, nurses who in direct contact with patients have own attitudes and values toward work and reported real feelings and psychological standing than who didn't contact the patient care directly. Also, clinical nurses who used to apply patient care and nursing procedures, most are being sufficient numbers, and suitably owed various crosswise specialties and health settings. ${ }^{[5,19,20]}$ Without any doubt, all of us as researchers directed our concerns to our target which is patient care outcome and of course, nurses who are provide direct care are the ones who fit consideration and spotlighting.

Published by Sciedu Press
The majority of study sample has a bachelor degree. There is an urgent need and significant nowadays to hire professionals with bachelor level of nursing science, particularly in Arabian countries. Bachelor nurses are equipped with proper knowledge and skills for competent nursing practice. Harmoniously with this speech, Horsburgh, and Ross in 2013 and Abdel Kader et al. in 2012 emphasized that nurses have to be well prepared by professional knowledge, skills, and values and then they can manage nursing work and any stressful experiences. Nursing education suggested to maintain bachelor and postgraduate nurses with direct patient care. ${ }^{[21,22]}$ Therefore, this result is expected and matched the requirement of the healthcare system world wide and especially in KSA.

More than one-half of the study subjects reported that they were passed through training programs that varied from two to seven days. This point is important for staff development for nurses and considered a great source of work motivation and proper methodology for supporting anxiety management among nurses. Congruent with this discussion, Waddell and Dunn in 2015 discussed that the staff development and training should be continuously and periodically. It is the heart of nurse manager activities which reflected in benefits for increasing staff nurses awareness, competencies, and motivation. Healthcare organization in any country should ensure the continuing staff training for knowledge and skills to improve their practice. Accordingly, the stakeholders and educators can bridge the distance between theory and practice. ${ }^{[23,24]}$

Concerning the first research question, table two and three provide enough data to explore and determine the levels of research variables. The revealed data, in Table 2, proved that the majority of study subjects have high scores in work motivation level in general, particularly in the three internalized types of motivation which are Interojected Regulation, Identified regulation and Intrinsic regulation. Nurses, who are internally motivated, will have the internal energy to work and manage work issues. Thus, this result specifies that the 
nurses have enough inner motives to be satisfied and gratified their work needs. Matching with this clarification, Gagné et al. in 2010 and Ryan \& Deci in 2000 discussed that when the employee does his/her best according to personal favor, she/he is internalized pushed to work better. Internalized motivations in introjected, intrinsic and identified regulation types are the most instruments that mainly, internally motivated any individual. Also, Kamanzi \& Nkosi in 2011 mentioned that the degree and awareness of internalized motivation at work, determine how and to what extent a nurse obligates and achieves her/his responsibilities optimally and professionally. ${ }^{[8,9,24]}$

Contrary to this line, Warr in 2013 explained that the happiness and satisfaction in work could be strongly associated with the extrinsic regulation type of work motivation, that depends on to which extend the employee recognized the value of the external motivation. External motivation can be used to meet the internalized motives, and then the employee becomes highly motivated internally and externally. ${ }^{[10,24,25]}$ More or less, we should support that the nurse workforce needs to be continuously motivated by all types of motivation, particularly, intrinsic types of motivation. Both intrinsic and extrinsic are completed each other's and directed the nurses' performance to best one.

For the discovered result in Table 3, all study subjects have a certain level of anxiety at work, but the majority of them has a low level. Therefore, there are minimal percents of the nurses have moderate or high Self-Rated Anxiety in work. It is a promising data in Saudi Arabia. But during conversations with some of the participants, they stated that "the anxiety must be present all the time because we faced several of difficult situations with patients and nursing management.' Anxiety level among all types of employees should be diminished to zero as possible, especially among nurses who are working in a vital job such as patient care. Supporting to this finding, Dike in 2013 reported that the analysis of work risks on employee's health should be considered particularly, for psychological risk. Burnout, frustrations, depression, and anxiety are silent hazards, which affecting negatively on work performance and productivity. Furthermore, a minimal level of anxiety among employees is accepted and can be managed efficiently, but high levels of it will hinder the work achievement. ${ }^{[25,26]}$ Additionally, many research investigations proved that there is a positive correlation between job anxiety and absenteeism, migration and turnover of the employees. The determination of job anxiety level among employees has to be settled in priorities and concerns of healthcare organizations census. ${ }^{[6,27]}$ Moreover, in a study among teachers, the authors found that there is a negligible ratio of teachers who are suffering from anxiety. ${ }^{[28]}$
In contrast to this current result, in Brazil, Schmidt et al. in 2011 found that anxiety is arising with higher incidence levels among nursing professionals. The author clarified that there are a lot of triggering factors around nurses which can enhance anxiety and restlessness, particularly in work environment and process regarding: shifts' schedule, team relation, work overload, and patients care. ${ }^{[29]}$ In nursing work there are huge factors that can aggravate anxiety and other psychological upset, but in the current result, the study participants seemed to have appropriate coping and adaptation methods with work climate and its triggers, because they have a low level of anxiety in work.

Concerning the correlation between nurses' level of motivation and self-rated anxiety, the current finding confirmed that there is an inverse relationship between them. The highest percentage of registered nurses who have low self-rated anxiety scores, is about, the same highest percent of them who have high work motivation scores. This result is congruent with the research hypothesis. Alternatively, there are no registered nurses who have high work motivation level, reported high self-rated anxiety. The correlation coefficient among self-rated anxiety and work motivation is noteworthy opposite relation among study subjects. This result was expected, and this is natural and recognized by insight and logical reasoning. Because and according to the self-determination theory, the internally motivated person will have limited psychological disturbance. Furthermore, and consistent with the self-determination continuum, the organization can anticipate the perfect performance of the employees who are motivated, engaged in decisions and psychologically stable. Thus, highly motivated employees, of course, will have a limited degree of work-related anxiety.

Congruent with this finding, AbuRuz ME in 2014 conducted a comparison between Jordanian and Saudi nurses in relation the impact of stress on job satisfaction. He mentioned that stress and anxiety adversely influence healthcare professionals' subjectivity and consequently reflected on poor work achievement. Anxiety and stress in nursing work are growing because of the problematic nature of the nursing job, but with recognition and motivation, nurses can overcome and adjust. Anxiety at work among nurses may decrease work motivation and vice versa. ${ }^{[11,13,14]}$ Moreover, Toode in 2014 and 2015 stressed that job-related anxiety is positively related with work withdrawal, and work frustration, but it has an inverse correlation with work motivation, satisfaction, and emotional gratification. ${ }^{[5,6,30]}$ Likewise, Kudo in 2010 reported that in the introjected regulation type of motivation, the individual tries to do all behaviors to keep away from guilt feeling and anxiety or stress. ${ }^{[5,31]}$ Therefore, motivation is adversely correlated with anxiety. Alternatively, limited 
motivation perhaps leads to high anxiety level, frustration, and emotional exhaustion.

As well and supported to the exits study result, in the last decade in 1999, De Jonge et al. ${ }^{[32]}$ found that job related anxiety and turnover intention have been increased among individuals who have low level of work motivation. In the same line and in the same year, Janssen et al. ${ }^{[33]}$ found also, that one of the specific determinants of low work motivation is the job related anxiety and burnout.

Furthermore in 2005, Bégat et al. ${ }^{[34]}$ found that there are significant positive correlations were identified between the nurses' well-being profile and between engagement and work motivation. But there is a negative correlation between their well being and physical illness symptoms and work related anxiety. Bégat concluded that nurses confront ethical conflicts and poor work motivation as source of job-related stress and anxiety. Clinical nursing management has a constructive effect to elevate nurse's work motivation and alleviate their feeling of anxiety. Globally, psychosocial work has an apparent influence on nurse's experience of having or not having work motivation. In addition and recently, Moura et al. in $2017^{[35]}$ stressed that nursing leadership has a noteworthy impact on the work motivation of healthcare professionals. Motivated nursing professionals can increase their retention and their production. However, there is an inverse correlation between leadership and turnover, stress and anxiety at work. Therefore, it is clear from all mentioned studies that work motivation has opposite relation and negatively correlated with job related anxiety.

Disagree with this finding and according to Maslow in 1954, who reported that if the individual has a specific need, it is considered a drive to encourage him/her to do required tasks. Maslow clarifies that the stress and anxiety are needs and have a visible effect on neurosis - producers rather than on motivation, so, they do not make trouble. So, Anxiety can be a source of motivation. ${ }^{[36]}$ It means that anxiety can produce sensory encouragements and empower to enhance ones' motivation.

Therefore, and in many countries; Arabian and non Arabian, shortage of healthcare professionals is a serious and dangerous phenomena on healthcare organizations' outcomes and national economics. Matching to this point, Al-Mutairi in 2015 in KSA, discussed that the kingdom has an extreme need for workforce professionals in nursing with different qualifications, ages, and nationalities. Thus it is a big challenge in KSA to maintain a national workforce of nurses. Globally, Saudi nurses contain only $29.1 \%$ of the whole nursing workforce. The rates of physicians and nurses in Saudi Arabia are 16 and 36 correspondingly per 10,000 residents, smaller than in additional countries which face the challenge such as Bahrain (30 and 58 per 10,000) and Kuwait (18 and 37 per 10,000). Even, in non-Arab countries the rate is limited, for instance: in Japan (12 and 95 per 10,000), Canada (19 and 100 per 10,000), France (37 and 81 per 10,000) and the United States of America (27 and 98 per 10,000). All nursing researchers all over the world should asses and determine the factors affecting nurses work motivation negatively or positively. Consequently, they can guide Nurses Managers to prepare fitting plans to overcome the negative factors and promote the positive ones. ${ }^{[17,37,38]}$ All over the world, nurses have to be motivated and satisfied in their work to reserve the national personnel force, particularly in KSA. Health care system in any country should follow effective and efficient rewarding and promotion means to enhance nurse's job retention and ensure their satisfaction. Investigation of work motivation and self-rated anxiety among nurses is a significant issue for nurses' researcher and managers and thus, suitable work motivation plans and emotional coping methodologies will be implemented. As a result, suitable incentives and motivation approaches among registered nurses will be tailored and supervised according to nurses' needs and preferences. Nurses have different personalities, background, values, and perceptions and at the same time confronted several of challenged experiential situations and patient's struggles or conflicts. Therefore, and worldwide, it is a necessity for nurses to be motivated and recognized at work without any contrary factors.

Finally, according to the study results and mentioned researches, the current study spotlights an exceptionally data about the relationship between work motivation and work rated anxiety, in Jeddah, KSA. There is no any evidence that handle those variables among nursing workforce, so the current study is a unique to investigate such correlation between the perceptions of work motivation and job anxiety. The present study clarifies that nurses who perceive a higher level of work motivation will have low anxiety level and can easily control it. Therefore, work motivation considered a useful tool to enhance employee emotional status and relieve work anxiety, especially among registered nurses. Accordingly, Nurse Manager should plan for effective motivational strategies for nurses and ensure their psychological status stability, because, optimal emotional health status among nurses will be reflected in perfect performance.

\section{Conclusions}

Supporting the finding of the current study, Saudi registered nurses in King Abd El Aziz governmental hospital, have high work motivation level scores with low self-rated anxiety scores. There is an opposite and converse correlation 
between both study variables. As a consequence, it is recommended that Saudi nurses should be aware by the importance of motivation in their job and at the same time, be conscious of the risks of work-related anxiety. Nurse Managers have to tailor all factors to nurses in the environment, organizational structure and culture to be positively motivated and, at the same time, to alleviate any tendency of work-related anxiety. Besides, both variables are essential concepts to be handled adequately by the organization and stockholders. Furthermore, work motivation and anxiety should be involved and integrated into the nursing curriculum. Also, it is recommended to provide regular in-serves training programs to nurse managers to equip them to develop work motivation and anxiety adjustment strategies for nurses. Fur-

\section{REFERENCES}

[1] Adjei KA, Emmanuel O, Forster OM. The Impact of Motivation on the Work Performance of Health Workers (Korle Bu Teaching Hospital): Evidence from Ghana. Hospital Practices and Research. 2016; 1(2): 47-52. https://doi.org/10.20286/hpr-010245

[2] Lambrou P, Kontodimopoulos N, Niakas D. Motivation and job satisfaction among medical and nursing staff in a Cyprus public general hospital. Human Resources for Health. 2010; 8: 26. PMid: 21080954 https://doi.org/10.1186/1478-4491-8-26

[3] Pinder CC. Work motivation in organizational behavior. 2nd ed. New York: Psychology Press; 2008.

[4] Dar S, Zehra N, Ahmad F. Extrinsic Factors Strong Motivators for Nurses in the Tertiary Care Hospitals. Pakistan Journal of Medicine and Dentistry. 2014; 3(1): 31-36.

[5] Toode K, Routasalo P, Helminen M, et al. Hospital nurses' individual priorities, internal psychological states and work motivation. International Nursing Review. 2014; 61(3): 361-370. PMid: 25091088. https://doi.org/10.1111/inr.12122

[6] Toode K, Routasalo P, Helminen M, et al. Hospital nurses' working conditions in relation to motivation and patient safety. Nursing Management. 2015; 21(10); 31-41. PMid: 25727441. https: //doi.org/10.7748/nm.21.10.31.e1293

[7] Ormrod J. Human learning. 3rd ed. Upper Saddle River, NJ: PrenticeHall; 1999. 13-44 p.

[8] Gagné M, Forest J, Gilbert MH, et al. The Motivation at Work Scale: Validation evidence in two languages. Educational and Psychological Measurement. 2010; 70: 628-646. https://doi.org/10.1177/ 0013164409355698

[9] Ryan RM, Deci EL. Intrinsic and extrinsic motivations: classic definitions and new directions. Contemporary Educational Psychology. 2000; 25: 54-67. PMid: 10620381. https://doi.org/10.1006/ ceps. 1999.1020

[10] Warr P. Jobs, and job-holders: Two sources of happiness and unhappiness. In S. A. David, I. Boniwell, \& A. C. Ayers, the Oxford Handbook of Happiness. Oxford: Oxford University Press; 2013 733-750 $\mathrm{p}$.

[11] AbuRuz ME. A comparative study about the impact of stress on job satisfaction between Jordanian and Saudi nurses. European Scientific Journal. 2014; 10(17): 162-172. ther researches are necessary such as: identify the effect of the work motivation educational program on nurse manager's leadership skills. A study of the relationship between work motivation and other negative or positive variables in work environment among nurses is needed. Also, investigation the work motivation and anxiety by different tools such as value test, emotional inventory and adjustment skills measurement.

\section{ACKNOWLEDGEMENTS}

The authors are thankful to the Deanship of Scientific Research through the Research Center at the College of Nursing, King Saud University for the support of this research project.

\section{CONFLICTS OF INTEREST DisClosure}

The authors declare they have no conflicts of interest.

[12] Basu S, Andrews J, Kishore S, et al. Comparative Performance of Private and Public Healthcare Systems in Low- and Middle-Income Countries: A Systematic Review. PLoS Med. 2012; 9(6): e1001244. PMid: 22723748. https://doi.org/10.1371/journal.pmed .1001244

[13] Green GF, Whitfield K. The non-material aspects if the employee work experience: trends and distribution, Chapter 2 in Whitfield, K. Employee Wellbeing and Working Life: towards and Evidence Based Policy Agenda. 2009.

[14] Jones MK, Latreille PL, Sloane PJ. Job Anxiety, Work-Related Psychological Illness and Workplace Performance. The Institute for the Study of LaborIZA Discussion Paper No. 5809. 2011.

[15] Buhai S, Cottini E, Westergard-Nielsen N. The impact of workplace conditions on firm performance. Tinberg Institute Discussion Paper No 2008-077/3. 2008.

[16] Alshmemri M. Job satisfaction of Saudi nurses working in Saudi Arabian public hospitals. School of health sciences, discipline of nursing and midwifery. Royal Melbourne Institute of Technology, published Phd thesis. Jordan University; 2014. 1-33 p.

[17] Rosner B. Fundamentals of Biostatistics: Solutions Manual. 5th ed. 1999.

[18] Warr P, Cook J, Wall T. Scales for the measurement of some work attitudes and aspects of psychological well-being. Journal of Occupational Psychology. 1979; 52: 129-148. https://doi.org/10.111 1/j.2044-8325.1979.tb00448.x

[19] Freitas AR, Carneseca EC, Paiva CE, et al. Impact of a physical activity program on the anxiety, depression, occupational stress and burnout syndrome of nursing professionals. Rev. Latino-Am. Enfermagem. 2014; 22(2): 332-6. PMid: 26107843. https ://doi.org/ 10.1590/0104-1169.3307.2420

[20] Abdel El-Halem GE, El Hawashy ZI, Gamal El-Dein AA, et al. Undergraduate Male Nursing students' Perception about the Image of the Nursing Profession. Journal of American Science. 2011; 7(3): 614-23.

[21] Horsburgh D, Ross J. Care and compassion: the experiences of newly qualified staff nurses. Journal of Clinical Nursing. 2013; 22(7/8): 1124-1132. PMid: 23480502. https://doi.org/10.1111/jocn .12141 
[22] Abdel Kader AM, Mohamed EA, Abood SA. Perception of Nurse Interns about Clinical Assignment Preparation Requirements. Journal of American Science. 2012; 8(12): 676-682.

[23] Waddell DL, Dunn N. Peer Coaching: The Next Step in Staff Development. Journal of Continuing Education in Nursing. 2015; 36(2): 84-89.

[24] Kamanzi J, Nkosi ZZ. Motivation levels among nurses working at butare university teaching hospital, Rwanda. Africa Journal of Nursing and Midwifery. 2011; 13(2): 1119-1321.

[25] Awosusi O, Jegede AO. Motivation and job performances among nurses in the Ekiti State environment of Nigeria. International Journal of Pharma and Bio Sciences. 2011; 22(2): 583-595.

[26] Dike P. The impact of workplace diversity on organizations. Degree Programme in International Business. 2013; 1-57. Available from: https://www.theseus.fi/bitstream/handle/10024/ 63581/Thesisxx.pdf

[27] Yahaya A, Arshad K, Ismail J. Professionals. MIS Quarterly. 2009; 24(1): 141-168. In Occupational Stress and its Effects towards the Organization Management. Journal of Social Sciences. 2009; 5(4): 390-97. https ://doi.org/10.3844/jssp. 2009.390.397

[28] Riisgaard H, Søndergaard J, Munch M, et al. Work motivation, task delegation and job satisfaction of general practice staff: a crosssectional study. Family Practice. 2017; 34(2): 188-193. https: //doi.org/10.1093/fampra/cmw142

[29] Schmidt D, Dantas R, Marziale M. Anxiety and depression among nursing professionals who work in surgical units. Rev Esc Enferm USP. $2011 ; 45(2)$ : 475-81.

[30] Tummers LG, Den Dulk L. The effects of work alienation on organizational commitment, work effort and work-to-family enrichment. Journal of Nursing Management. 2013; 21(6): 850-859. PMid: 23919679. https://doi.org/10.1111/jonm. 12159
[31] Kudo Y. Enhancing work motivation for Japanese female nurses in small to medium-sized private hospitals by analyzing job satisfaction. The Tohoku Journal of Experimental Medicine. 2010; 220(3): 237-245. PMid: 20208420. https ://doi.org/10.1620/tjem. 2 20.237

[32] De Jonge J, Van Breukelen GJP, Landeweerd JA, et al. Comparing group and individual level assessment of job characteristics in testing the Job Demand-Control Model: a multilevel approach. Human Relations. 1999; 52(1): 95-122. https://doi.org/10.1177/00 1872679905200106

[33] Janssen PPM, De Jonge J, Bakker AB. Specific determinants of intrinsic work motivation, burnout and turnover intentions: a study among nurses. Journal of Advanced Nursing. 1999; 29(6): 13601369. PMid: 10354230. https://doi.org/10.1046/j.1365-2 $648.1999 .01022 . \mathrm{x}$

[34] Bégat I, Ellefsen B, Severinsson E. Nurses' satisfaction with their work environment and the outcomes of clinical nursing supervision on nurses' experiences of well-being - a Norwegian study. J Nurs Manag. 2005 May; 13(3): 221-30. PMid: 15819834. https : //doi.org/10.1111/j.1365-2834.2004.00527.x

[35] Moura AA, Bernardes A, Balsanelli AP, et al. Leadership and nursing work satisfaction: an integrative review. Acta Paulista de Enfermagem. https://doi.org/10.1590/1982-0194201700055

[36] Maslow AH. Motivation and personality. New York: Harper \& Row, Publishers, Inc.; 1954. 8-45 p.

[37] Al-Mutairi E. Healthcare Workforce Challenges in Saudi Arabia (A Brief Overview). 2015. Available from: www.csc.org.sa/ . . /Healthcare $\% 2$ Workforce $\% 20$ Gap $\% 20$ in $\% 20$ Saudi $\% 20$ Arabia.pdf

[38] Almalki MJ, Gerald GF, Clark M. The nursing profession in Saudi Arabia: An overview. International Nursing Review. 2011; 58(3): 304-11. PMid: 21848775. https://doi.org/10.1111/j.1466 $-7657.2011 .00890 . x$ 